\title{
A CASE OF CONGENITAL ANOMALY OF THE URINARY TRACT AND NEUROGENIC BLADDER
}

\section{Sia SF and Dublin $\mathbf{N}$}

Department of Surgery, Faculty of Medicine, University of Malaya, 50603 Kuala Lumpur, Malaysia

\section{Introduction}

Anomalies of the genitourinary tract occur in approximately $10 \%$ of the population and account for about one third of all congenital malformations in children (I). Congenital malformations involving the genitourinary system are major therapeutic challenges faced by the practising urologist.

\section{Case Report}

A 31 year old Chinese man with spina bifida presented with right loin pain and fever. Ultrasonography of the abdomen showed right hydronephrosis and absent left kidney. He had a long history of lower urinary tract symptoms mainly, frequency with occasionally difficulty in passing urine since childhood. There was, however, no history of urinary incontinence. A nephrostomy tube was inserted and antibiotic administered which successfully treated the urinary tract infection. Antergrade pyelography showed ureteric obstruction in the distal ureter at its ectopic insertion. The patient complained of loin pain when attempts were made at clamping the nephrostomy tube. Cystoscopy and ureteroscopy showed an ectopic ureteric insertion at the prostatic urethra (Figure I) and a huge dilated tortuous right ureter with gross hydronephrosis. The bladder was also trabeculated with saccules (Figure 2). The patient had mildly impaired renal function.

Urodynamics done showed a hypocompliant bladder $(10.7 \mathrm{ml} / \mathrm{cm} \mathrm{H} 20)$ with a maximum cystometric capacity (MCC) of $250 \mathrm{cc}$. (Maximum Pdet at MCC is $55 \mathrm{~cm} \mathrm{H20}$ ). Micturating cystourethrogram (MCU) showed grade 5 refluxing megaureter. The DPTA nuclear scintigraphy showed a grossly hydronephrotic right kidney with a glomerular filtration rate (GFR) of $52 \mathrm{ml} / \mathrm{min}$ with a prolonged drainage (> $60 \mathrm{mins}$ ). Plain radiograph showed spina bifida at L4, L5 and SI levels with scoliosis of the lumbosacral spine. Computerised tomography of the abdomen revealed absence of the left kidney.

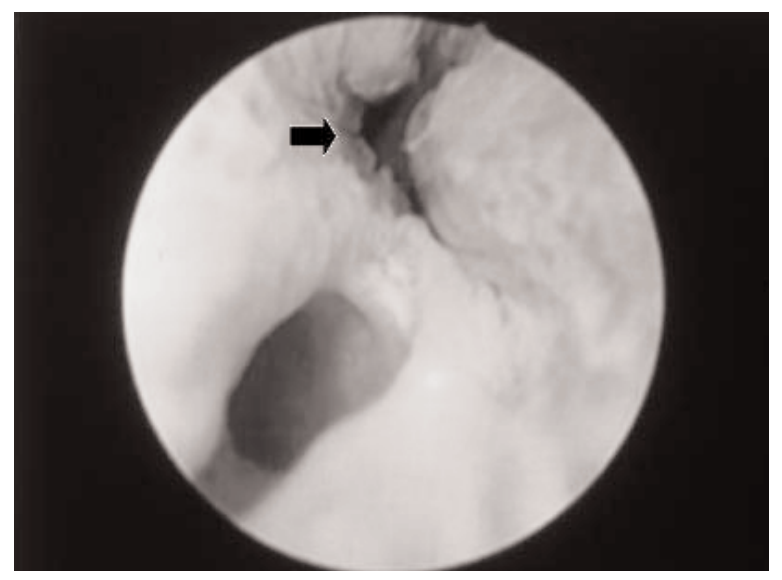

Figure I. An ectopic ureteric insertion at the prostatic urethra (arrow)

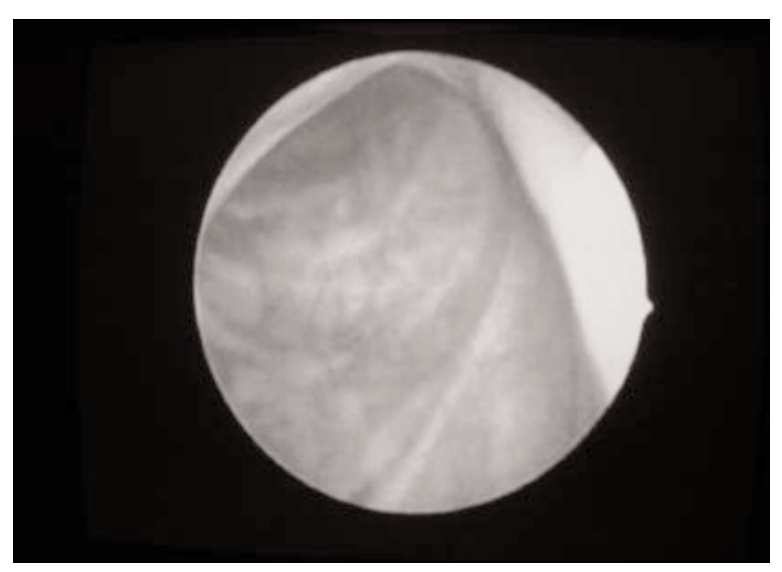

Figure 2. Endoscopic appearance of the trabeculated bladder with saccules

Correspondence:

Dr Sia SF

Department of Surgery

Faculty of Medicine

University of Malaya

50603 Kuala Lumpur

Malaysia

Tel: 603-7949 3852

Email: sfsia02@um.edu.my 
The patient subsequently underwent reimplantation of his right ureter (Figure 3 ) and an augmentation ileocystoplasty was done for his hypocompliant bladder. Post-operatively, he had to do clean intermittent catheterization $(\mathrm{ClC})$. In the first year after surgery, he had several episodes of UTI which were successfully treated with antibiotic. There was no evidence of deterioration in renal function.

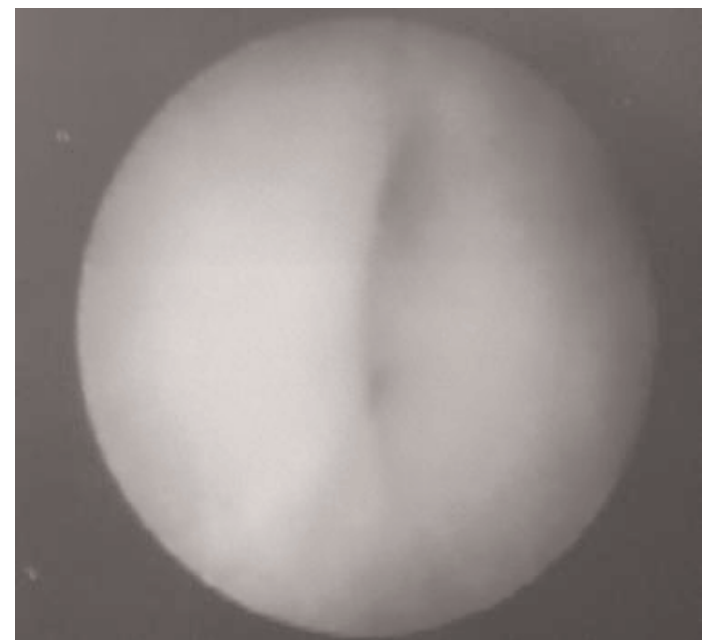

Figure 3. Tapered ureter implanted to bladder wall

\section{Discussion}

This paper presents a unique combination of malformations. Solitary kidneys are relatively rare with an incidence of approximately I in 1000 autopsies. In clinical practice, a solitary kidney is discovered approximately I in 1500 urological patients, and are twice as common in males as in females (2).

Ectopic ureters are relatively uncommon but their true incidence is uncertain because many are asymptomatic. Embryologically, the distal insertion of an ectopic ureter is the result of the ureteric bud arising more cephalad than usual on the mesonephric duct. Consequently, the ureter remains attached to the mesonephric duct longer, migrates more caudally than normal and is absorbed or inserted into either the urinary tract distal to the bladder or the repro- ductive tract. The most common sites of the ectopic ureteric insertion in male are posterior urethra (47\%), seminal vesicle $(33 \%)$, prostatic utricle $(10 \%)(3,4)$. Ectopic ureters can also drain into other wolffian duct structures, like the epididymis and the vas deferens. As all these locations are proximal to the external sphincter, males with ectopic ureters do not usually suffer from urinary tract infection but occasionally from constipation, pelvic pain, discomfort during ejaculation, and infertility (5).

The combination of a solitary kidney with an ectopic ureter is rare but the combination of an ectopic ureter of a solitary kidney with prostatic insertion, associated with an underlying neurogenic bladder and vertebral anomalies have not been reported previously to the best of our knowledge.

In conclusion, this unique case report stresses the importance of:

I. investigating a male patient with urinary tract infection;

2. congenital malformations of the genitourinary system could be associated with other complexed medical or developmental problems, as seen in this case of neurogenic bladder.

\section{References}

I. Rubenstein M, Meyer R, Bernstein J. Congenital abnormalities of the urinary system: a post-mortem survey of developmental anomalies and acquired congenital lesion in a children's hospital. J Pediatric 1961; 58,356 .

2. Brown, M. Congenital unilateral renal agenesis. Thesis. The University of California, Los Angeles, 1966.

3. Ellerker AG. The extravesical ectopic ureter. $\mathrm{Br}$ J Surg 1958: 45: 344-53.

4. Schlussel RN, Retik $A B$. Anomalies of the ureter. In Walsh PC, Retik AB, Vaughen ED Jr, Wein AJ, Eds. Campbell's Urology (7th edition), Vol 2, Philadelphia: WB Saunders, 1998; 1820-1829.

5. Squadrito J Jr, Rifkin MD, Mulholand SG, et al. Ureteral ectopia presenting as epididymitis and infertility. Urology 1987; 30:67. 